\title{
Teaching Teachers to Use Technology
}

David Geelan

School of Education

University of Queensland

Computers and other forms of information and communication technology have significant potential to enhance the experiences and outcomes of students in our schools, but an essential element of meeting that potential is providing teachers with the knowledge, skills and experiences that will lead to positive attitudes to the use of such technologies and strong self-efficacy in relation to their ability to integrate technology in their teaching practices.

'Teaching Teachers to Use Technology' is an edited collection of papers that was simultaneously co-published as an issue of the journal Computers in the Schools. The first nine chapters report specific examples of technology integration projects in US teacher education programs supported by the federally funded Preparing Tomorrow's Teachers to Use Technology (PT3) project. The final chapter considers whether the innovations arising from PT3 are likely to continue once the project funding ceases.

Many of the specific cases presented in the book are compelling - they show ways in which the provision of sufficient funding along with a structured approach can yield very significant changes in teacher education programs. A wide range of American colleges and universities is represented, along with examples of the development of preservice and inservice teachers and university faculty. All of the chapters cite growth and positive developments, but several also describe challenges and barriers to progress.

I have to admit that it took me a little while to adjust my expectations and to begin to read the book on its own terms. The title 'Teaching Teachers to Use Technology' led me to expect a more comprehensive approach to the subject, with consideration of the needs of inservice teachers as well as preservice. After all, many of the young teachers coming into our teacher education programs now already have quite strong technology skills and ideas for integrating technology with their teaching - it is some of the longer serving teachers who may be less familiar with technology and need more support. The book does talk to some extent about the development of inservice teachers, but largely through their recruitment as educational technology mentors to work alongside preservice teachers... and it could be argued that this process is likely to self-select the teachers who need least support with technology. Inservice teachers are beyond the planned scope of the book, and that is appropriate, but the title seemed a little misleading in this context.

Similarly, I think there would have been value in a foreword or introductory chapter from the editors that helped to orient the reader to the context of the papers presented, perhaps with some discussion of the goals and structure of the PT3 project. The projects discussed are actually of considerable interest to teacher educators outside the American system, for example, and this could have been discussed in such a chapter. Some consideration of the similarities and differences across the individual cases, and of emergent themes, might have helped make the book seem more cohesive and helped it achieve its potential more fully.

Two chapters in particular made an impression on me. David Gibson's 'Elements of Networkbased Assessment' explored the idea that 'doing assessment' of learning online is not simply a slightly poorer approximation of face-to-face learning and assessment, but in many ways a different activity with different affordances and possibilities. Gibson's chapter explores some of these with examples from his own practice, but more importantly lays out the beginnings of a theoretical framework, and explores the magnitude and the kind of work yet to be done in this area.

Linda and Joseph Lisowski and Sherry Nicolia's chapter about 'Doing More with Less' was inspiring because their innovations were driven less by the more usual 'technology is cool and is a part of life and students need to learn it for their jobs' interest and more by a concern for educational equity and providing opportunities for those who are currently educationally and technologically disadvantaged. They worked in a small private college, and worked with students in 
a poorly resourced urban school, and report the challenges and issues and joys of working with these students. The story has a less than happy ending, however - the lack of working technology in the urban district eventually defeated the project and they moved to collaborating with a better resourced suburban school, albeit with the continuing aim of producing committed, technologycapable teachers who would be able to enhance educational equity.

I learned useful things, and saw practical examples of important innovations, in all of the chapters, and found the book very fruitful in terms of my own teacher education practice and my aspirations to more fully integrate technology. I think other teacher educators both nationally within the US and internationally will benefit from reading 'Teaching Teachers to Use Technology' learning from others' experience is always valuable and can condense the learning experience (including the ability to avoid the pits into which others have fallen) when attempting similar innovations. 